This journal is the official publication of Bangladesh Society of Physiologists (BSP)

Web URL: www.banglajol.info/index.php/JBSP

Abstracted/indexed in Index Copernicus, Director of Open Access Journal, HINARI Index Medicus for South East Asia Region, Google Scholar, 12OR, infobse index, Open J gate, Cite factor, Scientific indexing services

pISSN-1983-1213; e-ISSN-2219-7508

Article

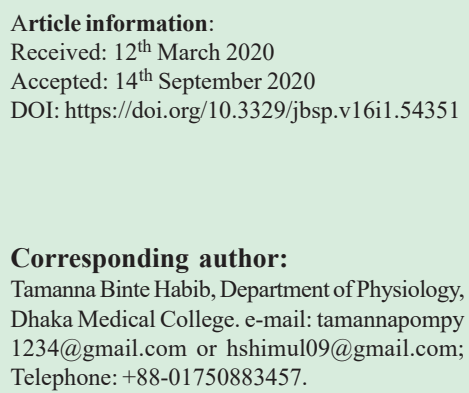

This article is open access licensed under CC BY NC SA which allows readers copy, distribute, display, and perform the work and make derivative works based on it only for noncommercial purposes.

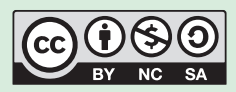

Volume 16 No. 1 June 2021: 39-43

\section{Effects of omega-3 fatty acid supplementation on serum Alanine Transferase and Aspartate Transferase levels in middle-aged patients with type 2 diabetes mellitus.}

\author{
Tamanna Binte Habib ${ }^{1}$, Qazi Shamima Akhter ${ }^{1}$ \\ 1. Department of Physiology, Dhaka Medical College, Dhaka.
}

Abstract

Background: People with type2 diabetes mellitus (DM) are at amplified chance of non-alcoholic fatty liver disease. Objective: To observe the effects of omega-3 fatty acid supplementation Alanine Transferase (ALT) and Aspartate Transferase (AST) in middle age patients with type $2 \mathrm{DM}$. Methods: A prospective interventional study in 2017, recruited 52 type 2 diabetic patients of both sexes aged 40 to 50 years. Among them, 27 patients were given fish oil capsule orally (omega 3 fatty acid $2 \mathrm{~g}$ /day) for consecutive 12 weeks and 25 patients without supplementation were selected as control also studied after 12 weeks. Serum ALT and AST of all patients were estimated by enzymatic colorimetric method at baseline and after 12 weeks. For statistical analysis, Paired Student's ' $t$ ' test and Unpaired Student's ' $t$ ' test were performed. Results: In this study ALT and AST significantly decreased in patients supplemented with omega-3 fatty acid after 12 weeks, ALT (alanine aminotransferase) and AST (aspartate transaminase) were decreased in diabetic patients after supplementation with omega3 fatty acid in comparison to control group. Conclusion: It can be concluded that omega-3 fatty acid supplementation was effective to reduce ALT and AST levels in diabetic patients and it may be helpful to minimize the risk of fatty liver in type- 2 DM.

Keywords: Diabetes Mellitus, Fatty liver, ALT, AST and Omega-3 fatty acid. 
Introduction

$\mathbf{T}$ ype 2 diabetes mellitus is a hormonal disorder characterized by hyperglycemia and hyperlipidemia and the

chronic hyperglycemia of type 2 diabetes is associated with long-term damage of liver causing fatty liver disease. ${ }^{1}$

Insulin is the hormone which is necessary for appropriate tissue development, growth and maintenance of whole body glucose homeostasis. ${ }^{2}$ Insulin resistance happens when the insulin sensitive tissue loses response to insulin. The basic effect of insulin resistance on glucose metabolism is to prevent the uptake and utilization of glucose by most cells of the body. As a result blood glucose concentration increases, cell utilization of glucose falls, utilization of fat increases and free fatty acid level increases in blood. ${ }^{3}$

w-3 Fatty acids are a group of polyunsaturated fatty acids consists of alpha- linolenic acid, eicosapentaenoic acid and docosahexaenoic acid found in sea fish (salmon, tuna and trout) and shellfish (crab, mussels and oysters) stimulates insulin sensitivity. 4

Consumption of fish oil can decrease free fatty acid level, promotes insulin sensitivity as well as reduce the incidence of type $2 \mathrm{DM} .^{5}$ Omega3 capsule act directly on insulin sensitive tissues, rises number of insulin receptors thus inhibits insulin resistance. ${ }^{6}$ Intake of food rich in omega3 fatty acid, particularly n-3 and n-6, facilitate the action of insulin through various metabolic pathways, including suppression of hepatic lipogenesis, decreased release of triglycerols from liver, improvement in ketogenesis, and oxidation of fatty acids in hepatic cells. ${ }^{7}$ Nonalcoholic fatty liver diseases are very common in type 2 diabetic patients. ${ }^{8}$ Nonalcoholic fatty liver diseases is the main cause of chronic liver diseases associated with diabetes mellitus. Liver plays an important role in the regulation of carbohydrate homeostasis, hepatocellular accumulation of glycogen causes abnormal elevation of Alkaline phosphatase and Aspartate aminotransferase. ${ }^{9}$ Moreover, intake of polyunsaturated fatty acid decreases serum ALT and AST level. ${ }^{10}$ Fish oil consumption reduces liver fat and ALT and AST by reducing circulating FGF21 levels in T2DM patients. Fibroblast related growth factor is an inflammatory markers that is related to NAFLD and T2DM, so when it reduces serum biomarker of liver also reduces and improvement occurs in T2DM patient. ${ }^{11}$

Omega- 3 fatty acid prevents this change by increasing peroxisome proliferator receptor gamma, increasing hepatic uptake and oxidation of free fatty acid in striated muscle. ${ }^{12}$ Therefore the present study is intended to assess the effect of supplementation of omega- 3 fatty acid in Bangladeshi diabetic patient on ALT \&AST to observe the liver function.

\section{Methods}

This prospective, interventional study was carried out in the Department of Physiology, Dhaka Medical College, Dhaka from January 2017 to December 2017 after approval from Research Review and Ethical Review Committee of Dhaka medical college, Dhaka. The patients were selected from outdoor of Endocrinology, Dhaka medical college and personal contact from Dhaka city by purposive sampling. At the beginning 60 diagnosed type- 2 diabetic patients of both sexes with the age ranging from 40-50 years with FBG $7.0 \mathrm{mmol} / \mathrm{l}$ or $126 \mathrm{mg} / \mathrm{dl}, \mathrm{HbAlc}$ $6.5 \%$, serum total cholesterol $>200 \mathrm{mg} / \mathrm{dl}$, serum triglyceride $>150 \mathrm{mg} / \mathrm{dl}, \mathrm{LDL}>130 \mathrm{mg} / \mathrm{dl}$, BMId" $30 \mathrm{Kg} / \mathrm{m}^{2}$ and patients with oral hypoglycemic drug and fatty liver were enrolled. 30 patients were given supplementation with Omega-3 fatty acid for 12 consecutive weeks and 30 patients were without supplementation and uses as control. Serum ALT and AST of all patients are assessed at baseline and after 12 
weeks. The control subjects studied at before and after 12 weeks of follow-up. After selection, the nature, purpose and benefits of the study were explained to each subject and informed written consent was taken from participants. Anthropometric measurement of the subjects was recorded and blood pressure was measured. All the information were recorded in a prefixed questionnaire. With aseptic precaution, $5 \mathrm{ml}$ of venous blood after overnight fasting was obtained from ante-cubital vein by a disposable plastic syringe from each subject for biochemical tests. Serum ALT and AST was estimated by enzymatic colorimetric method in auto-analyzer. Omega-3 fatty acid (2gm) in the form of fish oil capsule was supplied to patients free of cost and they were asked to take orally twice daily for 12 weeks with proper directions. Fish oil capsule were purchased from the local market. Patients were instructed not to change their diet and physical activities during the course of the study. A regular telephonic communication and periodic visit was made to participants to ensure the intake of capsule. After 6 weeks of study period, 3 patients were relinquished from study group and 5 patients were dropped out from control group. Finally, data of 27 patients under supplementation and 25 type diabetic patients without supplementation were used for analysis. Fatty liver was diagnosed by abdominal ultra- sonography. Subjects having history of heart disease, endocrine disorder, insulin therapy, viral hepatitis, acute or chronic infections, pregnant and lactating women were excluded from this study.

For statistical analysis, Paired Student's 't' test and Unpaired Student's ' $t$ ' test were performed as applicable using SPSS for windows version 16.0.Datawere expressed as mean $\pm \mathrm{SD}$. The $p$ value of $<0.05$ was accepted as level of significance.

\begin{abstract}
Results
In this study no significant difference were seen in age, sex, BMI, systolic and diastolic blood pressure between study and control group (Table I).In this study, the mean serum ALT and AST levels were almost similar and there is no statistical difference were observed at baseline. After 12 weeks of supplementation of fish oil serum ALT $(\mathrm{p}<.0 .01)$ and mean serum AST (p0.01) level significantly decreased. Again the mean serum ALT levels and mean serum AST levels were not significantly different in post follow up compared to baseline value in patients without supplementation. Moreover, serum ALT (p 0.01) levels and mean serum AST (p 0.01) levels were significantly lower and in post supplemented group compared to post follow up control group.
\end{abstract}

Table I: General characteristics of the patients in both groups $(\mathrm{N}=52)$

\begin{tabular}{|c|c|c|}
\hline Parameters & Supplemented T2DM(n=27) & Control group $(n=25)$ \\
\hline Age (years) ${ }^{\mathrm{a}}$ & $45.90 \pm 3.80$ & $44.92 \pm 3.75$ \\
\hline Male $^{b}$ & $18(66.7 \%)$ & $11(44 \%)$ \\
\hline Female $^{b}$ & $9(33.3 \%)$ & $14(56 \%)$ \\
\hline $\operatorname{BMI}\left(\mathrm{kg} / \mathrm{m}^{2}\right)$ & $25.03 \pm 2.27$ & $25.87 \pm 1.75$ \\
\hline $\mathrm{SBP}(\mathrm{mmHg})$ & $119.07 \pm 7.08$ & $121.79 \pm 4.47$ \\
\hline $\mathrm{DBP}(\mathrm{mmHg})$ & $79.63 \pm 6.26$ & $80.00 \pm 0.00 ?$ \\
\hline Duration of DM a (years) & $5.43 \pm 1.50$ & $5.35 \pm 1.57$ \\
\hline $\mathrm{TG}(\mathrm{mg} / \mathrm{L})$ & $154.68 \pm 27.08$ & $166.80 \pm 21.09$ \\
\hline HDL & $38.84 \pm 3.67$ & $29.96 \pm 4.43$ \\
\hline
\end{tabular}

Results were expressed as mean \pm SD. a $=$ Unpaired Student's ' $t$ ' test was performed to compare between the groups. $b=$ Chi Square test was performed to compare male and female between the groups. The test of significance was calculated and $p$ value $<0.05$ was accepted as level of significance. $\mathrm{N}=$ total number of subjects, $\mathrm{n}=$ number of subjects in each group $\mathrm{ns}=$ non-significant $* / * * / * * *=$ significant. T2DMS=Type 2 diabetes mellitus with supplementation T2DM=Type 2 diabetes mellitus without supplementation

Volume 16 No. 1 June 2021: 39-43 
Table II: Serum alanine transaminase and serum aspartate transaminase levels in different groups $(\mathrm{N}=52)$

\begin{tabular}{|c|c|c|c|c|}
\hline \multirow[t]{2}{*}{ Parameters } & \multicolumn{2}{|c|}{ Supplemented $(\mathrm{n}=27)$} & \multicolumn{2}{|c|}{ Control $(n=25)$} \\
\hline & Pre-suppl & Post-suppl & Prefollow-up & Post follow-up \\
\hline$\overline{\mathrm{ALT}(\mathrm{IU} / \mathrm{L})}$ & $34.6 \pm 2.71$ & $28.5 \pm 1.67^{* * \# \#}$ & $39.20 \pm 4.20$ & $39.96 \pm 4.43$ \\
\hline AST(IU/L) & $41.3 \pm 4.03$ & $38 . .5 \pm 1.02 * \#$ & $47.68 \pm 2.68$ & $46.8 \pm 2.20$ \\
\hline
\end{tabular}

Results are expressed as mean $\pm \mathrm{SD}$. $\mathrm{a}=$ Paired student's $\mathrm{t}$ test was performed for comparison within groups and $\mathrm{b}=$ unpaired $\mathrm{t}$ test was performed to compare between groups. $P$ value $<0.05$ was accepted as level of significance. $\mathrm{N}=$ total number of subjects, $\mathrm{n}=$ number of subjects in each group, ALT $=$ Alanine transaminase, AST $=$ aspartate transaminase $(*=$ study group baseline vs study group after 12 weeks of supplementation; \# = study group after 12 weeks vs control group after 12 weeks); $\left({ }^{*} p 0.01,{ }^{* *} p 0.001 ; \# \# p 0.001\right)$.

\section{Discussion}

In the present study, the mean serum ALT and AST levels reduced and high-density lipoprotein increased in patients of T2DM after supplementation with omega-3 fatty acid. Insulin resistance in T2DMcause impaired fatty acid oxidation in liver and subsequent accumulation of fat in liver. ${ }^{13}$ When diabetic patient suffers from non-alcoholic fatty liver diseases ALT and AST rises. ${ }^{14}$ Almost similar type of result were observed by other previous studies. ${ }^{15}$ Literature review suggested that, fat accumulation in liver leads to rise of serum triglyceride level which in turn cause rise serum ALT and AST levels due to impaired liver function. ${ }^{16}$ The binding of insulin with its receptor through releasing some inflammatory mediator from liver that decreases insulin receptor signaling activity, this facts are influenced by rising serum TG level.Omega3 fatty acid has a role on reducing serum triglyceride level. Peroxisome proliferator receptor-á exists in the liver which increase in number in presence of omega-3 fatty acid. An increase in PPAR-á leads to increased hepatic uptake of free fatty acid. It also increases the free fatty acids oxidation in skeletal muscle. ${ }^{17}$ As a result; free fatty acid level is reduced in blood. The consequence of free fatty acid reduction helps to decrease triglyceride synthesis. Thus, fish oil capsules reduces serum triglyceride level that promotes the binding of insulin to its receptor and improves insulin sensitivity. ${ }^{18}$ Fish oil activate PPAR-a (peroxisome proliferator activated receptor alpha) and down regulate sterol regulatory element binding protein-1c (SREBP-1) that improve fatty acid oxidation and reduces liver enzyme(ALT and AST).${ }^{19}$

\section{Conclusions}

After analyzing the results of the study, it can be concluded that supplementation of omega- 3 fatty acid can reduces serum ALT and AST levels in patients with type-2 diabetes mellitus. Therefore, omega-3 fatty acid containing diet may be useful to keep down the complications in type- 2 diabetes mellitus.

\section{Conflict of Interest: None}

Acknowledgement

The authors are thankful to the study subjects for their active, sincere and voluntary participation.

\section{References}

1. Jun DW, Kim HZ, Bae JH, Lee OY. The clinical significance of $\mathrm{HbAlc}$ as a predictive factor for abnormal postprandial glucose metabolism in NAFLD patients with an elevated liver chemistry. Hepatogastroenterology 2011; 58:1274-9.

Volume 16 No. 1 June 2021: 39-43 
2. Pessin JF, Saltie 1S. Signaling pathways in insulin action: molecular targets of insulin resistance. J Clin Invest 2000; 106(2): 155-169.

3. Delarue J, Magnan C. Free fatty acids and insulin resistance. Lipid metab and therap 2007;10(2): 1428.doi; $10.1097 /$ mco.0b013e328042ba90

4. Center for Complementary National and Integrative Health. Omega-3 supplements in depth. [Interenet] 2017[Cited on 2017 April 23]. Available from: http:// nccih.nih.gov//omega-3 supplements in depth/html

5. Albert BB, Derraik JGB, Brenan CM, Smith GC, Glarg ML, Smith DC, Hofman PL, Cutfield WS. Higher omega-3 index is associated with increased insulin sensitivity and more favorable metabolic profile in middle-aged overweight men. Sci Rep 2014; 6:1-8. Doi:10.1038/srep07928

6. Laila AZ, Lanza IR. Insulin -sensitizing effects of omega-3 fatty acids: lost in translation? Nutrients 2016; 8(6):1-24. Doi:10.3390/nu8060329

7. Portillo-Sanchez P, Bril F, Maximos M, Lomonaco R, Biernachi D, Orsak B, Subbarayan S, Webb A, Hecht J, Cusi K. High prevalence of Nonalcoholic Fatty Liver Disease in patients with type 2 Diabetes Mellitus and normal plasma Aminotransferase level. J Clin Endocrinol Metab 2015;100(6):2231-8.

8. Han Ni, Soe HH, HtetA. Determinants of Abnormal liver function tests in Diabetes patients in Myanmar. Int J Diabetes Res 2012;1(3): 36-41.

9. Mandal A, Bhattarai B, Kafle P, Khalid M, Jonnadula SK, Lamicchane J, Kanth R, Gayam V. Elevated Liver Enzymes in Patients with Type 2 Diabetes Mellitus and Non-alcoholic Fatty Liver Disease. Cureus 2018 ;23;10(11)

10. Parker HM, Johnson NA, Burdon CA, Cohn JS. Omega-3 PUFA supplementation and nonalcoholic fatty liver disease. J Hepatol 2012; 56:944-51.
11. Qin Y, Zhou Y, Chen S-H, Ran L, Zeng X-L, Ran L, Zeng X-L, Ying W, Chen J-L, Kang C, Shu F-R, Zhang Q-Y, Mi M-T. Fish oil supplementations lower serum lipids and glucose in correlation with a reduction in plasma fibroblast growth factor 21 and prostaglandin E2 in Nonalcoholic fatty liver disease associated with hyperlipidemia: A Randomized Clinical Trial. PloS One $2015 ; 10(7): 1-13$

12. Lopez AL, Ramos RV, Carrillo BE. Type 2 Diabetes, PUFAs and vitamin D: their relation to inflammation. J Immunol Res 2014; 1:1-14.

13. Bhat HB, Smith RJ. Fatty liver diseases in Diabetes mellitus. Hepatobiliary Surg Nutr 2015;4(2):101-108.

14. Shresta N, Bhatt NP, Neopane P, Dahal S, Regmi P, Madhav K, Shrestha R. Hepatic involvement with elevated liver enzymes in Nepalese subjects with Type2 Diabetes Mellitus. Int J Biochem Res Rev 2017;16 (1):1-8.

15. Ni H, Soe HHK, Htet A. Determinants of Abnormal Liver Function Tests in Diabetes Patients in Myanmar. Int J Diabetes Res 2012; 1:36-41.

16. Al-Jameil N, Khan FA, Arjumand S, Khan MF, Tabassum H. Associated liver enzymes with hyperlipidemic profile in type 2 diabetes patients. Int $\mathrm{J}$ Clin Exp Pathol 2015;7(7) 4345-49.

17. Shidfar F, Keshavaraz A, Hosseyni S, Ameri A, Yarahmadi S. Effect of omega -3 fatty acid supplements on serum lipids, apo-lipoprotein and malondehyde in type 2 diabetes patient. East Mediterranean Health J 2008;14(2):305-313.

18. Fernandez ML and West KL. Mechanism by which dietary fatty acids modulate plasma lipids. J Nutr 2005; 135:2075-8.

19. Xu J, Nakamura MT, PC Hyekyung, SD Clark. Sterol regulatory elementary binding protein -1 expression is suppressed by dietary polyunsaturated fatty acid. $\mathrm{J}$ Biol Chem 1999; 274(33);23577-83. 